REVISTA CHILENA DE LITERATURA

Noviembre 2011, Número 80, 117 - 133

\title{
MARIO VARGAS LLOSA: LA FICCIONALIZACIÓN DE LA HISTORIA EN LA GUERRA DEL FIN DEL MUNDO ${ }^{1}$
}

\author{
Horst Nitschack \\ Universidad de Chile \\ horst.nitschack@gmail.com
}

\section{RESUMEN / ABSTRACT}

En la novela La Guerra del fin del mundo Mario Vargas Llosa presenta una reescritura y ficcionalización del texto fundacional Os Sertões de Euclides da Cunha. El presente artículo sitúa esta novela en el momento de un cambio radical de las convicciones ideológicas y políticas de Mario Vargas Llosa en la década de los 70 y se propone analizar de qué manera las nuevas posiciones neoliberales asumidas por el autor se reflejan en la poética de la novela. Como argumento central se sostiene que en el proceso de ficcionalización del texto referencial de Euclides da Cunha se dejan descubrir dos estrategias: la primera es la individualización de

1 Este artículo es resultado de una investigación en curso, que se realiza en el contexto del Proyecto Fondecyt $\mathrm{N}^{\circ}$ 1085021: "La Bildungsroman o narrativa de formación en Brasil y Chile durante la segunda mitad del siglo XX y principios del XXI: jóvenes, subjetividad y ciudad". En las novelas urbanas del fin del siglo XX como A Cidade de Deus (1997) de Paulo Lins y Manual prático do odio (2003) de Ferréz, se encuentran significativos paralelismos con el texto fundacional de la literatura brasileña del siglo XX, Os Sertões. Estas correspondencias no solamente se dejan detectar en la tensión narrativa entre referencialidad y ficcionalidad, sino también en el hecho de que se trata de la primera manifestación literaria de conflictos sociales que se convierten en verdaderas guerras civiles y en la intención de encontrar explicaciones para la disposición a los actos más violentos. Esta temática narrativa, que sufre en el transcurso del siglo XX un desplazamiento del campo a la ciudad, conforma uno de los "grandes relatos" de la literatura brasileña de ese período. En este contexto, no deja de ser una curiosidad significativa que "favela", nombre dado a los barrios de miseria, esté directamente relacionado con Canudos: los veteranos de esta guerra, que recibieron parcelas en las cercanías de Río de Janeiro donde podían construir cabañas, dieron a este lugar el nombre de un cerro ubicado cerca de Canudos, "Favela", donde se encontraba el servicio médico y un improvisado hospital militar durante la guerra. 
la Historia, es decir, la narración privilegia las experiencias subjetivas de los protagonistas para explicar sus disposiciones a la violencia; en la segunda, la ficcionalización asume una paradoja: finge representar lo irrepresentable advirtiendo al mismo tiempo al lector que se trata solamente de ficción, es decir, ella responsabiliza al propio lector en qué medida él está dispuesto a identificar la narración con la 'verdad' histórica. En los dos casos nos encontramos frente a una poética que valoriza la responsabilidad individual y lo subjetivo en vez de la dependencia individual de lo colectivo y del compromiso de la narración con la historia objetiva.

Palabras clave: ficcionalización, referencialidad, individualización, violencia, Canudos.

In the novel The War of the End of the World (La guerra del fin del mundo) Mario Vargas Llosa presents a rewriting and fictionalization of Euclides da Cunha's foundational text Os Sertões. The article relates this novel to the radical change in Mario Vargas Llosa's ideological and political convictions in the 1970s and intends to analyze how the author's neo-liberal positions are reflected in the poetics of this novel. The central argument is that in this process offictionalization of Euclides da Cunha's text, two strategies can be discovered: the first being the individualization of History, that is, the narrative privileges the subjective experiences of the characters to explain their disposition to violence; the second refers to the fictionalization's paradox of pretending to represent the unrepresentable while letting the reader know that it is just fiction. In other words, the reader has to decide to what extent s/he is willing to identify the narration with the historical "truth". In both cases we are dealing with a poetics that values individual and subjective responsibility instead of the individual's dependence on the collective or the narrative's commitment to objectify history.

KEY WORDS: Fictionalization, referentiality, individualization, violence, Canudos.

La guerra del fin del mundo (1981), sexta novela de Mario Vargas Llosa y la primera en la cual éste se aparta del Perú como escenario ficcional, es sin duda la obra más violenta del escritor peruano hasta hoy, a pesar de que el gobierno y la dictadura de Rafael Leonidas Trujillo (1891-1961) de República Dominicana en La Fiesta del Chivo (2000) es responsable de más víctimas de lo que ha sido la Guerra de Canudos (1896-97) en el Nordeste brasileño, trasfondo histórico de esta novela. Ella es al mismo tiempo una novela histórica y una novela de guerra que narra todas las atrocidades que producen las guerras más violentas, a saber, las guerras civiles. La violencia como la disposición a las prácticas más bárbaras, pero a veces también más sofisticadas, de terror y de tortura del ser humano por él mismo, es uno de los temas principales de esta novela, que se convierte -en mi lectura- en una búsqueda literaria de las causas de este sado-masoquismo colectivo. El responsable de esta disposición para cometer los actos más inhumanos es-según Vargas Llosa- el fanatismo, tanto religioso como político, un fanatismo que encuentra sus razones de ser-según el autor-en las biografías de los sujetos. 
El intertexto que está presente en toda la novela es Os Sertões (1902) de Euclides da Cunha (1866-1909), libro considerado como uno de los textos fundacionales de la literatura brasileña. Se trata de un texto híbrido ejemplar que se sitúa en el 'in-between', el entre espacio, entre texto documental, descripción científica (practicando una transdisciplinaridad entre geografía, geología, etnología, sociología e historia) y relato biográfico (las experiencias vividas por Euclides da Cunha en su participación en la cuarta expedición militar contra Canudos): es un texto que se legitima por su carácter referencial. Pretende relatar 'la realidad' y ser 'verdadero' usando en extenso una retórica que produce 'el efecto de lo real' (Barthes 81-90). Busca convencer al lector del compromiso del autor con la realidad al presentarle hechos y acontecimientos históricos, es decir, presentar la tragedia nacional con la cual se fundó la República con un discurso que se legitima por la intención de la reproducción de los hechos reales.

$\mathrm{Si}$ aceptamos estas reflexiones o descripciones de ambos textos como punto de partida para el análisis de la diferencia entre los discursos que ellos representan, encontramos al mismo tiempo las razones principales de estas diferencias: se opone el interés y la intención de Euclides da Cunha de revelar las condiciones objetivas de la tragedia brasileña a la intención ficcional de Mario Vargas Llosa y su interés por las disposiciones subjetivas que hacían posible esta barbarie sado-masoquista. Es decir, se oponen o entran en competición dos escrituras literarias: la escritura referencial que pretende revelar la realidad objetiva y la escritura ficcional que pretende reconstruir la dimensión subjetiva de los acontecimientos objetivos e históricos. Esta última toma el mundo objetivo con sus acontecimientos históricos como material que le sirve de base para la construcción de un mundo subjetivo y se atreve a realizar interpretaciones que no se justifican con respecto a esa realidad objetiva, sino en el propósito de influenciar -o formar-el imaginario de los lectores.

Ambas escrituras deben ser analizadas en el contexto de la historia de las ideas de su tiempo.

Euclides da Cunha es aun hijo del positivismo en su variante spenceriana que fue divulgada con mucho énfasis por Silvio Romero, autor de la primera historia de la literatura brasileña (1888). La composición de Os Sertões muestra claramente esta postura y convicción positivista: en los primeros dos capítulos intitulados 'A terra' y 'O homem' se despliegan los fundamentos de los acontecimientos históricos que provocan la guerra de Canudos, tema del último capítulo. 
La situación en las décadas del 70 y 80 del siglo XX es ideológicamente muy distinta. Es sabido que la biografía de Mario Vargas Llosa está marcada por una ruptura ideológica en los inicios de los años setenta. El socialista convencido se transforma en un liberal y después en un neoliberal militante. Esta ruptura ideológica, sin embargo, también puede ser interpretada desde otra perspectiva, como continuación y como defensa de una misma idea con medios diferentes, en el sentido de que solo quien cambia sigue fiel a sí mismo. La idea y la convicción fundamental de Vargas Llosa sería, vista desde esta perspectiva, la de la necesidad de la modernización de América Latina. Hasta el inicio de los años setenta la ideología y los métodos económicos y científicos del socialismo se presentaron como una opción que podía competir con el proyecto capitalista de modernización. Sin embargo, a partir de esta época las deficiencias económicas y políticas del socialismo real se vuelven cada vez más evidentes ${ }^{2}$. En este sentido, el famoso 'caso Padilla' parece un pretexto apropiado para el cambio político de Vargas Llosa hacia la ideología de un capitalismo liberal ${ }^{3}$. La razón más profunda es el hecho de que cada vez se hace más obvio que el sistema capitalista ofrece mejores condiciones que el sistema socialista para la modernización necesaria de las sociedades latinoamericanas. Sin dudas, este cambio ideológico tiene consecuencias en la poética de Mario Vargas Llosa. Si echamos una mirada a sus publicaciones literarias se muestra claramente lo siguiente: las tres grandes novelas totales, es decir, las novelas que pretenden presentar una visión total de la sociedad peruana (La ciudad y los perros (1963), La Casa verde, (1966) y Conversación en la Catedral (1969)) fueron escritas antes de 1971. Las novelas de los setenta Pantaleón y las visitadoras (1973) y La tía Julia y el escribidor (1977) frustraron a muchos lectores de la época que esperaron de Vargas Llosa la continuación de su realismo totalizante. La mayoría de los críticos las declararon como novelas inferiores en comparación a las

${ }^{2}$ El espectáculo simbólico en esta contienda entre los dos sistemas, es decir, de la competencia entre la URSS y los Estados Unidos, fue la corrida por la conquista del espacio que terminó en 1969 con el alunizaje y el triunfo estadounidense.

${ }^{3}$ El "Caso Padilla": "El poeta Herberto Padilla había criticado en 1971 en su libro Fuera del juego el devenir de la Cuba postrevolucionaria. Tras su detención se sometió a una autocrítica pública, en la que se inculpó a sí mismo de actividades contrarrevolucionarias para obtener la liberación. Este caso fue el disparador de que una gran parte de los escritores latinoamericanos, para los cuales la Cuba socialista era hasta poco antes una esperanza histórica, se distanciaran de ella" (Nitschack, Mario Vargas Llosa: Potencia e impotencia de la ficción 491). 
primeras, respecto a su valor literario. Solamente la crítica (postmoderna) a partir de los noventa se atrevió a rescatar estos textos y descubrió su valor literario (Penzkofer 58-59; Berg 37-54).

En La guerra del fin del mundo, de 1981, el escritor peruano aparentemente presenta de nuevo una novela realista, totalizante. Sin embargo, esta vez no faltan críticos que le reprochan la insuficiencia de su realismo y constatan que la novela totalizadora "entra en crisis" (Schlickers 186) y que "la técnica fragmentaria" (desarrollada con tanto éxito principalmente en La casa verde y en Conversación en la Catedral) "se muestra incapaz de aprehender racionalmente la realidad extraliteraria y representarla" (Schlickers 186).

Pero, ¿si mostrar una realidad extraliteraria, en este caso la realidad de la Guerra de Canudos, tema del gran libro de Euclides da Cunha, no fuera el objetivo primordial de Vargas Llosa en esta novela? ¿si el compromiso con el lector no fuera un compromiso referencial, es decir, representar la realidad factual, sino un compromiso fíccional, es decir, referirse e influenciar el imaginario del lector?

Una reorientación estética como ésta correspondería completamente a la reorientación política de Vargas Llosa: la mudanza desde una convicción socialista a una convicción (neo)liberal implica estéticamente la reevaluación de lo individual y de la subjetividad con respecto a lo social, la que supone, al menos, una independencia relativa del mundo de las ideas con respecto al mundo social e histórico, y la posibilidad del primero de influenciar al segundo. En otras palabras, y contra Marx y su tesis sobre Feuerbach: cambiar el mundo a través de su interpretación ejerciendo un impacto sobre el imaginario de los lectores ${ }^{4}$.

Pues, si aceptamos La Guerra del fin del mundo como un texto fíccional, entonces debemos asumir también que los elementos históricos y sociales que sirven como material narrativo de la novela no están en función de una reivindicación de la referencialidad, sino de la intención de influenciar al lector al nivel de su imaginario y de sus conceptos ideológicos.

${ }^{4}$ La referencia filosófica para esta reorientación ideológica de Vargas Llosa era Karl Popper y su obra La sociedad abierta y sus enemigos ( $1^{\mathrm{a}}$ edición en inglés en 1945). El autor peruano descubrió a este filósofo a finales de los años setenta, "luego de haber perdido el entusiasmo por la utopía revolucionaria" y cuando comenzaba "una revalorización de la cultura democrática” (Vargas Llosa, Mi deuda con Karl Popper 224). 
El discurso referencial y el discurso ficcional en Os Sertões y La Guerra del fin del mundo, respectivamente, se distinguen por los siguientes criterios: en el primer texto el discurso referencial, en sus distintas manifestaciones (discurso sociológico, histórico, etnológico, geológico etc.) se pone al servicio de 'la realidad' con la intención de presentarla de la manera más fiel y más auténtica posible. Su transformación en habla es considerada como un acto que en última instancia está completamente a servicio de esta realidad y la hace aparecer como está de hecho. Sin embargo, a pesar de los esfuerzos y de los diversos discursos utilizados, el discurso referencial nunca consigue captar completamente esta 'realidad' que siempre se revela más compleja que el discurso referencial propiamente tal. Lacan lo ha tematizado en sus reflexiones sobre la relación entre lo real, lo simbólico y lo imaginario, en las que constata que los registros de lo simbólico y de lo real siempre quedan en deuda, marcados por la insuficiencia o deficiencia frente a lo real ${ }^{5}$.

En La guerra del fin del mundo el discurso ficcional utiliza el discurso referencial de Os Sertões como intertexto, respetando su compromiso con la realidad y la representación de ésta, pero sometiéndolo a la economía de la narración ficcional. Vargas Llosa busca crear un mundo imaginario que entre en diálogo con el imaginario del lector. Se produce entonces un juego complejo, en el cual ambos, tanto el mundo imaginario que ofrece el texto ficcional como la imaginación del lector, se resignifican mutualmente. Ello implica, entre otras cosas, que para el discurso ficcional la relación narración -público (el efecto) (Gadamer, cit. en Rall 19-29) sea más importante que la relación narración- realidad extraliteraria.

Consecuentemente, estos dos discursos suponen pactos diferentes con el lector: el pacto referencial se caracteriza por la identificación entre narrador y autor, donde este último garantiza al lector que su discurso se somete a la factualidad, con el compromiso de reproducirla fielmente (como en el caso de Euclides da Cunha). La experiencia vivida por el autor o por testigos fehacientes es la base de la narración. La consecuencia es una retórica que se muestra convencida de que discurso y realidad prediscursiva son idénticos. Ésta utiliza las estrategias más distintas para suprimir la brecha entre ambos (lo que siempre constituye un engaño, tanto para el autor como para el lector). El relato referencial se dirige entonces principalmente a un público que se

${ }^{5}$ Lo 'real' para Lacan se define exactamente por esta imposibilidad de representación. "Lo real no es el mundo. No hay la menor esperanza de alcanzar lo real por la representación" (Lacan 82). 
interesa por un contacto real, vívido, con la realidad narrada, es decir, se dirige a un lector que busca orientación e información sobre dicha realidad.

Por otro lado, en el pacto ficcional realista el lector está consciente de que el narrador finge o inventa 'realidad'. No juzga el texto según su compromiso con la facticidad sino por su verosimilitud. Esta realidad ficticia se presenta como si fuera realidad, y produce un juego doble: admite que no es realidad pero insiste en que podría serla- y una realidad todavía más verdadera que la propia realidad ${ }^{6}$, es decir, el discurso ficcional promete 'iluminar' a través de sus narraciones la ceguera del discurso referencial frente a 'la realidad' inaccesible.

El procedimiento poético más exitoso en este caso consiste en el enriquecimiento del discurso referencial con la dimensión subjetiva otorgándole así la potencialidad de convencer al lector y, al mismo tiempo, ejercer un impacto en su imaginación que el discurso referencial difícilmente alcanza. Así el discurso ficticio completa la historia objetiva con acciones entre personajes históricos e inventados, con eventos e historias vividas por ellos, con toda la complejidad de sus sentimientos y expectativas, deseos, temores y frustraciones, lo que finalmente lo hace parecer más real que el discurso referencial. Esta carga del texto narrado con subjetividad produce una 'plusvalía' del discurso ficcional realista en comparación con el referencial. No importa si la narración ficticia realista parte de la propia Historia, la vida social o los procesos psíquicos de los personajes que vivieron o podrían haber vivido aquella experiencia en particular. Su potencialidad no radica en la representación de la Historia, cuyo final está determinado y es conocido (por ejemplo, la hecatombe de Canudos) sino en su interpretación, que se expone sirviéndose de historias inventadas (en el caso de La guerra del fin del mundo la mayor parte de los personajes de la novela son ficticios) dándole un aspecto plástico y concreto. Si el "engaño" del discurso referencial consiste en su promesa de hacer desaparecer la brecha entre discurso y 'realidad', el discurso ficcional realista asume esta brecha, la puentea con la ficción y juega con el "engaño", entregando la responsabilidad al propio lector, si está dispuesto a tomar la narración como 'realidad' y con ello como verdad.

${ }^{6}$ Mario Vargas Llosa habla en varias oportunidades de "la verdad de la mentira" (Vargas Llosa, La verdad de las mentiras) (Nitschack, Mario Vargas Llosa: Potencia e impotencia de la ficción). 
El trabajo literario de Vargas Llosa consistió entonces en esta ficcionalización del texto referencial de Euclides da Cunha, en el intento de conseguir lo que el propio autor brasileño tenía que admitir que le era imposible lograr: dar una explicación de cómo esta erupción de la violencia, tanto del lado de la población del Sertón como del lado de las tropas oficiales, había sido posible. A pesar de recurrir a una variedad de teorías científicas para encontrar esta explicación, Euclides concluye el libro con la observación: "Duas Linhas. É que ainda naõ existe um Maudsley para as loucuras o os crimes das nacionalidades..." (781) ${ }^{7}$.

En La guerra del fin del mundo las cuatro campañas de Canudos se transforman en una guerra paradigmática en la cual los valores de la civilización occidental, que son los que el proceso de modernización promete cumplir, están en juego. Vargas Llosa integra Canudos al imaginario occidental y éste le sirve como un medio, como un pretexto, para tematizar una de las grandes amenazas del mundo civilizado moderno: la erupción de la violencia irracional y la recaída en la barbarie, consecuencia -en la interpretación propuesta en este novela-del entusiasmo fanático provocado por un fundamentalismo religioso de un lado y político del otro. Espacialmente, esta amenaza tiene carácter universal: está presente tanto en el 'fin del mundo', como en cualquier sitio del centro. En el sentido temporal de un milenarismo apocalíptico también: la idea del fin del mundo es la fuente de un dogmatismo absurdo y altamente destructivo que encuentra su razón de ser, según el autor, en una disposición del inconsciente humano, que Freud identificó en su tercera tipología como 'pulsión de muerte' (Freud). Así la tensión muerte-amor (en sus manifestaciones más variadas) puede ser identificada como el segundo leitmotiv de la novela, entrelazado de modo muy complejo con el de la violencia.

Para Vargas Llosa, Canudos pierde el carácter de un evento singular y se convierte en un fenómeno que puede surgir en cualquier parte. No es solamente, como en el texto de Euclides da Cunha, una región en el Brasil donde se decide el destino de la joven República, tampoco solamente una guerra contra un fanático religioso, Antônio Conselheiro, y sus seguidores milenaristas. La apropiación del texto de Euclides da Cunha ${ }^{8}$ en La guerra

${ }^{7}$ Henry Maudsley (1835-1918): psiquiatra inglés que desenvuelve una teoría sobre las relaciones entre y la locura y el crimen.

${ }^{8}$ No se trata únicamente de este texto, pero es el intertexto principal. Ver el estudio de Leopoldo Bernucci, donde se analiza en detalles cuales son los intertextos de Vargas Llosa. 
del fin del mundo convierte a Canudos en materia prima de una novela de la literatura universal (Weltliteratur). Por medio de la ficcionalidad, Vargas Llosa consigue transformar Canudos en un lugar como lo es Macondo, de Cien Años de Soledad o Comala, de Pedro Páramo: el pueblo no pierde su sustrato geográfico e histórico, sin embargo, el interés principal del autor no es el de representar en primer lugar ese sitio geográfico, sino tomarlo como espacio de acción para una narración que trata de la condición humana. En consecuencia, el interés que se despierta en el lector no es histórico, sino que radica en la fascinación por la propia narración que presenta ejemplos (ficticios) de esta 'condición humana'. Canudos, pues, se transforma de esta manera en un paradigmático lugar latinoamericano, en un espacio donde los valores éticos de la modernidad están puestos en cuestión ${ }^{9}$, tanto por un movimiento popular herético y retrógrado como por un Estado que abusa de su poder y su aparato técnico más moderno (el ejército) ${ }^{10}$.

La novela logra así la 'universalización', resultado de la ficcionalización del material entregado por Euclides da Cunha, esencialmente mediante las siguientes operaciones literarias:

1. La introducción de personajes ficticios (el anarquista Galileo Gall, el periodista miope, el guía Rufino, su esposa Jurema, el enano y el grupo del circo y el Barón de Canabrava ${ }^{11}$, principalmente) y la interacción entre estos personajes ficticios y los personajes históricos (Antônio Conselheiro, Moreira César, comandante de la tercera campaña contra Canudos, General Arturo Guimarães comandante de la cuarta campaña, Carlos Machado de Bittencourt, ministro de guerra en estos años, quien organizó personalmente la última campaña). De esta combinación de personajes históricos y ficticios resulta un multiperspectivismo narrativo que permite la descripción de los eventos históricos desde posiciones

${ }^{9}$ Con respecto a esta problemática existen paralelos significativos entre Civilización y Barbarie de Sarmiento y el libro de Euclides da Cunha.

${ }^{10}$ Es significativo que Euclides da Cunha da mucha importancia al hecho de que la victoria final se debe a un administrador seco, sin entusiasmo militar y sin sentido de heroísmo, el marechal y ministro de guerra Carlos Machado de Bittencourt.

${ }^{11}$ Esta figura fue inspirada por el Barão de Jeremoabo, el hacendado más poderoso del nordeste de Brasil en las últimas décadas del siglo XIX. Pero, como en el caso del 'periodista miope' (que se queda sin nombre en toda la novela) que algunos críticos proponen identificar con el propio Euclides da Cunha, predomina claramente la parte ficcional sobre la referencial, que en el caso del periodista además es altamente especulativa. 
políticas e ideológicas contrarias: no solamente el contraste entre el fanatismo milenarista de Antônio Conselheiro y sus seguidores, por un lado, y la misión civilizadora del gobierno representado por los generales y el ministro de guerra, por otro, sino también la visión anarquista de Galileo Gall, la observación distanciada e imparcial del 'periodista miope', las reflexiones basadas en un canon valórico conservador-ilustrado del barón. Debido a este panorama diversificado de personajes y posiciones ideológicas el narrador parece dejar al lector la tarea de formar su propia opinión y realizar un juicio personal de los acontecimientos, sirviéndose de una razón que tiene valor universal. La responsabilidad individual del juicio y de la acción que -según el narrador- en el fondo tienen que asumir todos los personajes de la novela, se repite así también en el nivel del lector. Que la posibilidad de asumir tal responsabilidad individual sea resultado de la construcción literaria -y en última instancia de la convicción ideológica del autor-no se encuentra tematizado en ninguna parte.

2. Los acontecimientos de la historia oficial, consecuencia de la política nacional e internacional, forman un contraste con la microhistoria, en cuyo centro se encuentra la figura de Jurema y en su destino se incorpora la historia local, popular y cotidiana del Sertón. Su vida está marcada por la relación con cuatro hombres que representan cuatro extremos de esta existencia 'al fin del mundo', que, sin embargo, reflejan al mismo tiempo alternativas de la condición humana o, más precisamente, de la condición femenina en general: la dependencia sumisa de su esposo Rufino, hombre del Sertón arraigado en su naturaleza y cultura, su violación por el extranjero y anarquista fanático Gallileo Gall, la persecución por el amor del yagunzo Pajeú, ferviente admirador de Antônio Conselheiro, y finalmente su relación amorosa con el 'periodista miope', intelectual del mundo urbano, perdido tanto como ella en este conflicto al cual se ven expuestos, que se ven obligados a asumir, y frente al cual están forzados a actuar, a pesar de que la contingencia histórica no ofrece ninguna explicación lógica del porqué se encuentran envueltos en esta catástrofe.

3. Finalmente, la dimensión subjetiva, con la cual la narración trata tanto a los personajes históricos (Antônio Conselheiro y los militares de la República) como a los inventados, ofrece al lector -también al lector completamente ajeno a este mundo del Sertón y a sus prácticas y hábitosla posibilidad de comprensión e identificación con los sentimientos, expectativas y reacciones emocionales de cada uno de los personajes 
de la novela. Otra vez se trata de una subjetividad "universalizada", que suprime completamente la otredad radical con respecto a cualquiera de las figuras cuya vida fue marcada y cicatrizada por estas experiencias y que ningún lector del mercado de libros donde esta novela tenía y tiene éxito consigue imaginarse.

En comparación con el intertexto de Euclides da Cunha el trabajo literario de Vargas Llosa consiste principalmente en esta individualización de los caracteres, otorgándoles su propia subjetividad y llenando la macrohistoria con innumerables eventos, acontecimientos y episodios de una microhistoria en la cual se mueven los individuos concretos que-absurdamente-encuentran esta concretización mediante la ficción. En este trabajo literario se demuestran las posibilidades que ofrece el género novelesco en toda su ambigüedad: la dimensión subjetiva otorga al texto referencial una plusvalía que hace desaparecer la brecha entre 'realidad' y texto, pero ésta crea al mismo tiempo la ilusión de la subjetividad literariamente escenificada, que permite, no obstante, una aproximación identificadora entre lector y los sujetos de un mundo para él completamente desconocido.

Esta ambigüedad se hace evidente en la historia ficticia que se inserta en la historia oficial de Canudos y contrasta de forma significativa con ella: la narración que se despliega con el trío 'periodista miope' - Jurema enano. Estos protagonistas no pertenecen a ninguno de los grupos políticos o religiosos, provienen cada uno de contextos sociales completamente diferentes, se mueven entre los frentes, sin rumbo y sin representar ninguna convicción religiosa o política, con el único objetivo de salvar sus vidas. Los tres sobreviven finalmente y, aun más, la catástrofe de Canudos se convierte en el tiempo feliz de sus vidas: el amor entre Jurema y el periodista y el reconocimiento del enano como ser humano por parte de ambos (471-476). En la contingencia de sus destinos individuales no se 'refleja' ni la historia objetiva, ni una totalidad social, ni una lógica o causalidad histórica. Aquí la propuesta literaria de Vargas Llosa se distancia completamente de Euclides da Cunha cuyo texto está marcado por el esfuerzo (frustrado al final, como hemos citado arriba) de encontrar por medio de la ciencia, los discursos geográficos, sociales e históricos las razones que son responsables de la barbarie que se ha producido en Canudos. El realismo ficcional de Vargas Llosa en esta fase literaria no elabora más personajes con el carácter de 'tipos', propios de la estética lukacsiana que encontramos en sus grandes novelas totalizantes, como Alberto o Jaguar en La Ciudad y los perros, representantes de grupos 
sociales limeños, o Zavalita en La conversación en la Catedral, quien incorpora todo el malestar de la clase media peruana. Contra la ideología marxista / socialista, el Vargas Llosa que políticamente se ha pronunciado a favor del neoliberalismo, no construye una relación lógica y causal entre las historias individuales y la Historia, con $\mathrm{H}$ mayúscula. La propia tragedia de Canudos está interpretada como consecuencia de casualidades que en el fondo serían evitables, si existiera la 'buena voluntad' entre los participantes de resolver los conflictos en el plano comunicativo, es decir por negociación. Contra Euclides da Cunha que busca en los discursos científicos más distintos las razones de este fanatismo destructor y contra las convicciones marxistas para las cuales los fanatismos y violencia son el resultado de represiones sociales, Vargas Llosa insiste en la interpretación individualista y busca en la población de estas regiones, en la socialización individual de cada uno y no en las condiciones sociales generales, la disposición a convertirse en yagunzos crueles e inexorables.

Euclides da Cunha escribe Os Sertões-desde la perspectiva de los vencedores, claro está, con muchas simpatías por los vencidos-como la comprobación de sus convicciones positivistas y de su teoría racial: para la formación de una futura gran nación brasileña se necesita una raza homogénea formada de las tres razas principales que constituyen su población: los indígenas, los negros y los blancos. Esta nueva raza, una raza de 'titanes' se formó en el Sertón. Su valentía, su valor, su resistencia se demostró en la guerra de Canudos: "Ademais entalhava-se o cerne de uma nacionalidade. Atacava-se a fundo a rocha viva da nossa raça" (da Cunha 766). Vargas Llosa transforma Os Sertões en una novela ficcional que alerta el lector de los peligros del dogmatismo político y religioso, fuente de un fanatismo destructor y de la disposición a la violencia más bárbara.

Con esta reescritura, como hemos sostenido al inicio, Vargas Llosa entra en un diálogo con la discusión ideológica de los setenta y ochenta tomando posición contra la idea socialista, contra el colectivismo y la dominación del individuo por el Estado. Se pronuncia en favor de la posibilidad de la libertad individual aun en las circunstancias más dramáticas. Así por lo menos tenemos que leer la escena central del amor entre Jurema y el periodista miope en el medio de las condiciones más extremas de la hecatombe de Canudos (486-487).

Quisiéramos confirmar nuestras reflexiones teóricas con un breve análisis de la escena final de la novela. Se trata de una escena puramente ficcional en la cual se confrontan a modo de un "show-down" un coronel de la policía 
bahiana, Geraldo Macedo, y el Alférez Maranhão, oficial de las tropas del sur, famosas por sus crueldades contra los prisioneros. Se produce una pelea entre los nordestinos y los gauchos, sobre el trato de los prisioneros, en la que los segundos acusan a los primeros de simpatizar con los rebeldes y de la falta de una verdadera actitud republicana, una pelea que termina con que el Alférez Maranhão derriba a uno de los policías de Geraldo Macedo (527). Cuando éste, que estaba ausente porque se había dedicado a buscar entre los muertos a uno de los yagunzos más famosos, João Abade, en cuyo destino tenía un interés personal, se entera de este evento, va solo, demostrando su valentía como macho, al campamento de los gauchos, derriba a Maranhão y lo humilla frente a su tropa, orinando sobre él. Saliendo del campamento, una vieja que sabe que está buscando a João Abade se le acerca y le pregunta: “¿Quieres saber de João Abade?” "Quiero - asiente el Coronel Macedo. ¿Lo viste morir?". "Lo subieron al cielo unos arcángeles -dice, chasqueando la lengua. Yo los vi" (531). Fin de la novela.

La escena utiliza información que le ofrece el intertexto, Os Sertoes: la derrota final de Canudos, la masacre bárbara de prisioneros por parte de los soldados del ejército, las rivalidades que existían en el ejército entre las tropas que provinieron del sur (los gauchos) y las del Estado de Bahía, y la referencia a uno de los yagunzos más famosos, tanto por sus crueldades como, más tarde, por su sumisión incondicional a Antônio Conselheiro: João Abade.

El narrador explica doblemente la disposición a la violencia más cruel de João Abade, cuyo nombre de yagunzo era João Satanás, siempre en relación con su historia individual: por su identificación con Roberto el Diablo, cuya historia escuchó por primera vez en su infancia, y por el hecho de que su padre, que también era yagunzo, fue asesinado por el policía Geraldo Macedo que más tarde, cuando se había convertido en João Satanás continúa persiguiéndolo a él también (64-71). Este Geraldo Macedo participa, nos narra la novela, en la última campaña contra Canudos como coronel de un batallón de la policía bahiana, sabiendo que João Abade está entre los partidarios del Conselheiro. Se construye entonces una unidad narrativa que se funda en las experiencias subjetivas de los personajes, cuyos hilos se comienzan a tejer en los primeros capítulos para terminar en los últimos. La contingencia histórica y los destinos subjetivos se complementan maravillosamente como por una "mano invisible"12

12 "La mano invisible" es una metáfora de Adam Smith (1723-1790). Ella ordena de modo invisible el mercado libre. 
que es la de un autor soberano (Vargas Llosa). Paralelamente se concentran las tensiones políticas y culturales objetivas entre el sur y el nordeste en las reacciones subjetivas y el conflicto entre el coronel y el alférez, traducidas en manifestaciones de rivalidades entre subjetividades masculinas. También en estos casos, en el primero, su interés por el destino de João Abade, por el cual éste se siente individualmente responsable y su actitud deshumanizante con el alférez, y en el segundo, las contradicciones entre la defensa de la República y el actuar más bárbaro contra los prisioneros, un conflicto político regional está traducido en un conflicto de carácter universal entre machos. Finalmente, el "Yo los vi" de la vieja como voz popular, con la cual termina la novela, confirma la convicción del autor de que una hecatombe como Canudos no acaba con la superstición y la irracionalidad del pueblo sino, por lo contrario, la refuerza, en Canudos como en cualquier parte del mundo.

Resumiendo: con la sustitución del discurso referencial de Euclides da Cunha por la ficcionalidad, Vargas Llosa logra tres objetivos:

1. Ésta le permite escribir una novela multiperspectivista y polifónica en la cual se confrontan las posiciones más divergentes, hasta excluyentes. Esto implica que la narración no defiende la existencia de una perspectiva preestablecida que permita organizar y ordenar la Historia, sino que deja al lector la responsabilidad de otorgarle sentido, confirmando así, aparentemente, la posición ilustrada y antidogmática del autor.

2. Con la introducción de la subjetividad como fuerza histórica, Vargas Llosa evita un objetivismo ideologizado o cientista. Mientras Euclides da Cunha hace referencia a un sinnúmero de teóricos occidentales (criminólogos, psiquiatras, sociólogos, geógrafos, etc.) con el objetivo de encontrar una explicación científica para Canudos, Vargas Llosa, por lo contrario, inserta 'Canudos' en la discusión ideológica occidental de la época y defiende, usándolo como ejemplo, su posición neoliberal.

Por medio del énfasis en la subjetividad de los personajes (como uno de los ideologemas más importantes de la modernidad occidental) logra dar un carácter universal a los acontecimientos regionales en Canudos (historias de amor y desamor).

3. La ficcionalización permite a Vargas Llosa liberarse de las discusiones políticas y sociales típicamente brasileñas del fin del siglo XIX y actualizar el conflicto histórico de los Canudos para una discusión (ficcional) en torno al fanatismo, el fundamentalismo y la violencia. Esta intervención 
literaria no tiene como objeto la propia 'realidad' sino que se refiere ante todo al imaginario del lector.

Al comparar Os Sertões de Euclides da Cunha con la novela La guerra del fin del mundo de Vargas Llosa no interesa solamente el juego intertextual literario, sino que más importante aún es el cambio de escritura o de registro literario, es decir, el cambio de la referencialidad a la ficcionalidad; la sustitución de la representación de una realidad histórica por la creación de un mundo de subjetividades que entra en interacción con la 'materia prima' ofrecida por los discursos históricos, sociológicos, etc., resignifica a estos últimos y otorga a la dimensión del imaginario una potencialidad adicional.

Cierto es que la novela pierde así la autenticidad histórica y social de Os Sertões, pero con la subjetividad gana una nueva dimensión política que refuerza y confirma las nuevas convicciones ideológicas del autor, desde la concepción estética. Alejandro Losada que ya había comentado el giro ideológico del gran autor, hoy día finalmente Premio Nobel, en los años 70, antes de la publicación de La guerra del fin del mundo, lo hizo con las siguientes palabras: "No se puede discutir la validez de su obra, pero se debe preguntar de qué valor se trata” (Losada 127).

\section{BIBLIOGRAFÍA}

Barthes, Roland. "L'effet de réel”. Littérature et réalité. Roland Barthes et al. París: Ed. du Seuil, 1982. 81-90.

Berg, Walter Bruno. "Funktion und Technik des polyphonen Realismus bei Vargas Llosa". Das literarische Werk von Mario Vargas Llosa. Ed. José Morales Saravia. Frankfurt: Vervuert, 2000. 37-54.

Bernucci, Leopoldo, M. Historia de un Malentendido. Un Estudio Transtextual de La Guerra del Fin del Mundo de Mario Vargas Llosa. New York/ Bern/ Frankfurt am Main/ París: Peter Lang, 1989.

Castro-Klarén, Sara: "Locura y dolor. La elaboración de la historia en Os Sertões y La guerra del fin del mundo". Revista de Crítica literaria latinoamericana 10/20 (1984): 207-231.

Castro-Klarén, Sara. "Santos y Cangaceiros: inscription without discourse in Os Sertões and La guerra del fin del mundo". Hispanic Review 101/2 (1986): 366-388.

Cunha, Euclides da. Os Sertões. Editado por Leopoldo M. Bernucci. São Paulo: Ateliê Editorial, 2001.

Os Sertões. Edición crítica editada por Walnice Nogueira Galvão. São Paulo: Editora Ática, 2001. 
Freud, Sigmund. Jenseits des Lustprinzips. 1920. En Studienausgabe, Bd. III: Psychologie des Unbewussten. Frankfurt am Main: Fischer, 1975. 213-272.

Gárate, Miriam V. Civilização e Barbárie n'Os Sertões. Entre Domingo Faustino Sarmiento e Euclides da Cunha. Campinas: Mercado de Letras, 2001.

Köllmann, Sabine. Literatur und Politik. Mario Vargas Llosa. Bern: Peter Lang AG, 1996.

"Literature and politics in Vargas Llosa's fiction: La Guerra del fin del mundo". Vargas Llosa's Fiction \& the Demons of Politics. Köllmann, Sabine. Oxford/ Bern y otros: Peter Lang, 2002. 139-237.

Kristal, Efrain. Temptation of the World. The Novels of Mario Vargas Llosa. Nashville: Vanderbilt University Press, 1998.

Lacan, Jacques: "La Tercera”. Intervenciones y Textos 2. Jacques Lacan. Buenos Aires: Manantial, 1999.

Losada, Alejandro. Creación y práxis: La producción literaria como praxis social en Hispanoamérica y el Perú. Lima: Univ. Nacional Mayor de San Marcos, 1976.

Mac Adam, Alfred. "Euclides da Cunha y Mario Vargas Llosa". Revista Ibereoamericana 50/126 (1984): 157-164.

Nitschack, Horst. "Mario Vargas Llosa leyendo al Perú - el Perú leyendo a Mario Vargas Llosa”. Boom y Postboom desde el nuevo siglo: impacto y recepción. Eds. José Manuel López de Abiada y José Morales Saravia. Madrid: Ed. Verbum, 2005. 175-191.

"Mario Vargas Llosa: Potencia e impotencia de la ficción frente a la realidad". Texto social. Estudios pragmáticos sobre literatura y cine. Eds. Paatz Annettey Pohl Burkhard. Berlín: Edition tranvia, Verlag Walter Frey, 2003. 489-501.

Oelker, Dieter. "Mario Vargas Llosa: teoría y práctica del “elemento añadido"”. Atenea 431 (1975): 132-151.

Oviedo, José Miguel (Ed.). Mario Vargas Llosa. Madrid: Taurus, 1981.

Oviedo, José Miguel. Mario Vargas Llosa: invención de una realidad. Barcelona: Seix Barral, 1982.

Penzkofer, Gerhard. "Mimesis und Intertextualität: Überlegungen zur Entwicklung des Romanwerks von Mario Vargas Llosa”. Iberoamericana 58-59 (1995): 64-83.

Gadamer, Hans-Georg. "Fundamentos para una teoría de la experiencia hermenéutica". En: Rall, Dietrich. En busca del texto. Teoría de la recepción literaria. México D.F.: Universidad Nacional Autónoma de México, 1987. 19-29.

Rama, Ángel. "La guerra del fin del mundo: una obra maestra del fanatismo artístico". Eco 246 (1982): 600-664.

Schlickers, Sabine. "Conversación en la Catedral y La Guerra del Fin del Mundo de Mario Vargas Llosa: Novela totalizadora y novela total". Revista de Crítica literaria latinoamericana 48 (1998): 185-211.

Toro, Alfonso de. "La postcolonialidad en Latinoamérica en la era de la globalización. ¿Cambio de paradigma en el pensamiento teórico cultural latinoamericano?" El debate de la postcolonialidad en Latinoamérica. Una postmodernidad periférica o cambio de paradigma en el pensamiento latinoamericano. Eds. Alfonso de Toro y Fernando de Toro. Frankfurt/Main: Vervuert, 1999. 31-77. 
Vargas Llosa, Mario. La guerra del fin del mundo. Barcelona: Ed. Seix Barral, 1981. "La novela". Los novelistas como críticos. Tomo 2. Eds. Norma Klahn y Wilfrido H. Corral. México D.F.: Fondo de Cultura Económica, 1966. 341-359.

"El arte de la novela". El Arte de la novela. Mario Vargas Llosa, Dario Ruiz Gómez et al. Medellín: Ateneo Porfirio Barba Jacob, 2000. 9-32.

“Mi deuda con Karl Popper”. Encuentro con Popper. Madrid: Alianza, 1993. 222-232.

“La odisea de Karl Popper”. Homenaje a Karl Popper. Madrid: Fundación para el Análisis y los Estudios Sociales, 1995. 17-60.

“Mi deuda con Karl Popper”. Encuentro con Popper. Madrid: Alianza, 1993.

La verdad de las mentiras. Ensayos sobre la novela moderna. Bogotá: Peisa, 1996.

\section{BIBLIOGRAFÍA SOBRE FICCIÓN Y FICCIONALIZACIÓN}

Appel, Markus. Realität durch Fiktion. Berlin: Walter de Gruyter, 2005.

Benet, Vicente J. y Burguera Nadal, María Luisa. Ficcionalidad y escritura. Castelló de la Plana: Universitat Jaume I, 1994.

Blume, Peter. Fiktion und Weltwissen. Berlin: Erich Schmidt Verlag, 2004.

Domínguez de Rodríguez Pasqués, Mignon (coord.). Historia, ficción y metaficción en la novela latinoamericana contemporánea. Buenos Aires: Corregidor, 1996.

Genette, Gérard. Nouveau Discours du Récit. Paris: Editions du Seuil, 1983.

Fiction et Diction. Paris: Editions du Seuil, 1991.

Henrich, Dieter e Iser, Wolfgang (eds.). Funktionen des Fiktiven. München: Fink, 1983.

Hilmes, Carola. Das inventarische und das inventorische Ich. Grenzfälle des Autobiographischen. Heidelberg: Carl Winter, 2000.

Iser, Wolfgang. Das Fiktive und das Imaginäre. Perspektiven literarischer Anthropologie. Frankfurt: Suhrkamp, 1991.

Keller, Ulrich. Fiktionalität als literaturwissenschaftliche Kategorie. Heidelberg: Carl Winter, 1980.

Kimminich, Eva (ed.). Erfundene Wirklichkeiten. Literarische und wissenschaftliche Weltentwürfe - zwei Wege, ein Ziel? Jena: Schäuble Verlag, 1997.

Krauze de Kolteniuk, Rosa. Los seres imaginarios: Ficción y verdad en literatura. México: Universidad Ciudad de México, 2003.

Pacheco, Carlos. La comarca oral: la ficcionalización de la oralidad cultural en la narrativa latinoamericana. Caracas: Ediciones la Casa de Bello, 1992.

Peterson, Jürgen H. Mimesis, Imitatio, Nachahmung. München: Fink, 2000.

Die Fiktionalität der Dichtung und die Seinsfrage der Philosophie. München: Fink, 2002.

Sutrop, Margit. Fiction and imagination. The anthropological function of literature. Paderborn: Mentis, 2000.

Zipfel, Frank. Fiktion, Fiktivität, Fiktionalität. Berlin: Erich Schmidt Verlag, 2001. 